\title{
Efficacy of Ferrous Bisglycinate Chelate for the Management of Preoperative Anaemia in Orthopaedic Surgical Patients: A Prospective Study
}

Maria Beatrice Rondinelli ${ }^{1 *}$, Giovanni Inghilleri ${ }^{2}$, Marco Pavesi ${ }^{3}$, Antonella Di Bartolomei ${ }^{1}$, Roberta Pagnotta ${ }^{1}$, Daniela Fioravanti ${ }^{1}$, Paola ludicone ${ }^{1}$, Sandro Rossetti ${ }^{4}$, Francesco Pallotta ${ }^{4}$, Marco Bertini ${ }^{5}$ and Luca Pierelli ${ }^{1}$

${ }^{1}$ Department of Transfusion Medicine, San Camillo-Forlanini Hospital, Rome, Italy

${ }^{2}$ SIMT, AO Fatebenefratelli Oftalmico, Milan, Italy

${ }^{3}$ Department of Anestesiology, IRCCS Policlinico S. Donato, Milan, Italy

${ }^{4}$ Department of Orthopedic Surgery, San Camillo-Forlanini Hospital, Rome, Italy

${ }^{5}$ Department of $R \& D$, Laboratori Baldacci SpA, Pisa, Italy

"Corresponding author: Maria Beatrice Rondinelli, Department of Transfusion Medicine, San Camillo-Forlanini Hospital, Rome, Italy, Tel: +390658703546; E-mail: MRondinelli@scamilloforlanini.rm.it

Received date: Jan 09, 2016, Accepted date: Feb 07, 2016, Publication date: Feb 11, 2016

Copyright: ( $) 2016$ Rondinelli MB, et al. This is an open-access article distributed under the terms of the Creative Commons Attribution License, which permits unrestricted use, distribution, and reproduction in any medium, provided the original author and source are credited.

\section{Abstract}

Background: Oral iron support in patients (pts) undergoing preoperative autologous blood donation (PABD) programs has been suggested by different authors to improve red blood cell (RBC) production and limit iron depletion. Oral iron therapy, however, is frequently associated with side effects and poor pts compliance. The aim of this study was to evaluate the effectiveness of low doses of ferrous bisglycinate chelate (Tecnofer, Baldacci) a new oral iron preparation characterized by high gastrointestinal absorption and tolerability in the management of preoperative anemia.

Material and methods: In our hospital we used a multimodal approach of integrated alternatives strategies after a preliminary clinical evaluation (CE) that provides a supportive iron therapy. We enrolled 60 pts candidate for orthopedic surgery presenting hemoglobin $(\mathrm{Hb})$ levels between 11.5 and $12.5 \mathrm{~g} / \mathrm{dL}$ in order to evaluate the effectiveness of ferrous bisglycinate chelate for these pts who presented gastrointestinal side effects related to previous oral iron treatment. All pts pre-deposited 1 unit of PABD (400 mL) at day 0 . Forty pts (Group A) received 1 tablet/day of ferrous bisglicinate (14 mg/day) for 10 days. No iron was given to 20 pts (Group B). The variation in Hb concentration, percentage of reticulocytes (\% RET), serum ferritin (FER) and percentage of transferrin saturation (\%SAT) from the day of pre-deposit to ten days after donation were compared between the two groups.

Results: The study lasted From October 2014 to December 2014 baseline Hb, RET count, serum FER and transferrin saturation were similar in the 2 groups. Pts receiving iron therapy had a lesser iron depletion, an increased erythropoiesis which in turn limited $\mathrm{Hb}$ reduction due to PABD, without showing any side effects.

Discussion: Preliminary data of our study seem to indicate that oral administration of low doses of ferrous bisglycinate chelate is an effective and safe therapy to support PABD and to treat iron deficiency in patient's candidate for major surgery. The high patient's compliance to this new oral iron therapy seems to be a "Key Factor" in the treatment success.

Keywords: Preoperative anaemia; Preoperative autologous blood donation; Patient blood management; Oral iron; Ferrous bysglicinate chelate

\section{Introduction}

Many authors have shown the importance of the global scientific approaches of Patient Blood Management (PBM) toward the surgical patients. PBM relies on multimodal and multidisciplinary strategies that allow to detect and treat perioperative anaemia, to reduce surgical blood loss and the risk of perioperative coagulopathies, to harness and optimize physiological tolerance of anaemia [1].

The clinical evaluation (CE) of the surgical elective patients before surgery is very important, above all for the identification and diagnosis of the anemia's disease [2].
The preoperative anaemia is common in patients undergoing orthopedic and other major elective surgeries and it is associated with increased perioperative morbidity and mortality, in particular infectious complications and prolonged hospitalization.

A recent meta-analysis of 19 studies showed that $24 \%$ of patients undergoing total hip replacement (THR) or total knee replacement (TKR) and $44 \%$ of those with hip fracture had preoperative anemia; these studies have consistently shown that patients with preoperative anaemia have poorer outcomes than non-anaemic ones [3].

Although anaemia is a serious but easy to treat condition, preoperative diagnosis and treatment has almost never been routinely evaluated before surgery.

Actually the diagnosis and treatment of preoperative anaemia could be considered a milestone within the PBM. The diagnosis and 
Citation: Rondinelli MB, Inghilleri G, Pavesi M, Bartolomei AD, Pagnotta R, et al. (2016) Efficacy of Ferrous Bisglycinate Chelate for the Management of Preoperative Anaemia in Orthopaedic Surgical Patients: A Prospective Study. J Blood Disord Transfus 7: 339. doi: $10.4172 / 2155-9864.1000339$

Page 2 of 5

treatment of preoperative anaemia is time consuming and, therefore, its detection and assessment should be undertaken close to 28 days before the scheduled surgery to enable an adequate treatment [4].

The CE of the patient allows the diagnosis of the type of anemia and consequently the right therapeutic approach.

Many studies have shown that good preoperative $\mathrm{Hb}$ levels reduce the risk of exposure to allogeneic blood for surgical patients [5]. It has been suggested that $\mathrm{Hb}$ levels before elective surgery should be within the normal range defined by the World Health Organization (WHO; $>12 \mathrm{~g}$ dl-1 in women; $>13 \mathrm{~g}$ dl-1 in men). Iron supplementation therapy should be used to correct iron deficiency, in fact oral iron is effective in reducing the need for transfusion before orthopedic surgery, in particular in patients with iron deficiency anemia which represents the most common form of anemia in surgical patients. Many studies pointed out a decrease in patient's domiciliary compliance to oral iron therapy because of gastrointestinal side effects that induce the patient to discontinue oral iron therapy without reaching the therapeutic target (correction of the preoperative anemia) $[6,7]$. Oral iron salts administration is often responsible for gastrointestinal side effects because of the activity of free elemental iron on the gastrointestinal cells. Indeed, to find alternative with best patient's treatment compliance versus known oral iron salts, could represents a therapeutic benefit for surgical patients [8]. In ferrous bisglycinate chelate, ferrous ion is firmly bound to two molecules of glycine, this relationship allows the ferrous ion to pass the barrier without irritating the gastric mucosa. The iron chelate complex is subsequently absorbed as such at the intestinal level, leading to high bioavailability of elemental iron, and a total absence of interactions between iron and food .For this reason, the use of ferrous bisglycinate chelate (Tecnofer ${ }^{\oplus}$, Baldacci) does not imply the occurrence of all those annoying gastrointestinal symptoms such as nausea, vomiting, epigastric pain, heartburn, chronic pain, constipation or diarrhea [9-11].

Low ferrous bisglycinate chelate dosage $(0.5 \mathrm{mg}$ elemental iron/Kg body weight) has recently shown to be useful in restoring sideremia in children affected by sideropenic anemia secondary to celiac disease $[12,13]$.

Aim of this study was to evaluate the effectiveness of ferrous bisglycinate chelate (Tecnofer ${ }^{\circledR}$, Baldacci) in association with the PABD to prevent erythrocyte, hemoglobin and iron stores depletion in the surgical patients $[14,15]$.

\section{Materials and Methods}

The San Camillo Forlanini Hospital is a tertiary care hospital [16]. In agreement with the Departments of anesthesia and surgery, we have introduced a multi-phase integrated approach for patient's evaluation prior to major elective surgery which includes (CE), with specific care to hematologic status, supplementation treatment (ST), preoperative autologous blood donation (PABD) with or without erythropoietin (EPO) administration, peri-surgical $\mathrm{EPO}$ and a program of perioperative blood salvage (PBS), whenever possible and appropriate.

Our local protocol suggests that only patients for whom a request of a minimum of 2 RBCs units had been made, according to local maximum surgery blood order schedule (MSBOS), were enrolled in our procedures. Before the $\mathrm{CE}$, all patients were examined for blood cell counts, clinical chemistry, clotting parameters and iron status (serum iron, transferrin, ferritin and transferrin saturation), instrumental tests and investigations according to hospital procedures and the type of surgical intervention [17-19].

Sixty patients, who planned major orthopedic surgery, were enrolled in the study of those 29 pts for total hip replacement (THA) and 31 pts for total knee replacement (TKA). Fourthy pts (Group A) have completed the PABD adding daily administration of ferrous bisglycinate chelate (14 mg/day of elemental iron) for 10 days prior to surgery and twenty patients (Group B) have carried out the PABD without the administration of ferrous bisglycinate chelate therapy.

The choice of treatment with the bisglicinate chelate was determined by the report during anamnesis of major side effects with other therapies based on iron preparations. From the day of predeposit to ten days after donation, the following parameters were compared between the two groups from the day of pre-deposit to ten days after donation: $\mathrm{Hb}$ concentration $(\mathrm{Hb})$, percentage of reticulocytes (\%RET), serum ferritin (FER) and percentage of transferrin saturation (\%SAT).

In addition, in some patients with daily administration of the drug, we evaluated reticulocyte counts by using the ABX Pentra 120 Analyzer which allows proportional and absolute reticulocyte counts based on the measurement of RNA content revealed by thiazole orange, a fluorescent dye specific for nucleic acid.

The increase of circulating immature reticulocyte in comparison with the mature component suggested an increase of effective erythropoiesis.

The study primary end point was to find a significant difference in $\mathrm{Hb}$ value between groups at the end of treatment (10 days after PABD). The secondary end points were to confirm $\mathrm{Hb}$ difference between groups by Serum Ferritin value (FER), percentage of Transferrin Saturation (TSAT) and percentage of reticulocytes (RET).

The ratio between immature and mature reticulocytes has been investigated for some patients treated with TECNOFER in order to demonstrate an increase in effective erythropoiesis by using Ferrous Bysglicinate chelate therapy. Reticulocyte's maturity is classified into 3 subsets: low RNA content (RetL), medium RNA content (RetM) and high RNA content (RetH): global reticulocyte RNA content is quantified using a mean fluorescent index (MFI). The immature area (IMM) of the matrix include the high fluorescent elements classified as strongly immature reticulocytes and nucleated RBCs.

The immature reticulocyte fraction (IRF) is calculated using the sum of absolute count of RetH+RetM+IMM/Total Ret Count. This reticulocyte grading rather than the reticulocyte count may be a superior parameter in monitoring the erythropoietic activity induced by iron therapy.

Differences in side effects between groups have been analyzed during the clinical trial: Statistical analysis was performed with IBM SPSS Statistics Version 232015 on a MAC computer. The comparisons of the mean values of all quantitative variables in the two independent groups were performed with the one-way analysis of variance (ANOVA) procedure. The conventional P less than 0.05 criteria for significance for two-tails tests was adopted in the interpretation of the results.

\section{Results}

The patients' demographics and surgical characteristics are summarized in Table 1. 
Citation: Rondinelli MB, Inghilleri G, Pavesi M, Bartolomei AD, Pagnotta R, et al. (2016) Efficacy of Ferrous Bisglycinate Chelate for the Management of Preoperative Anaemia in Orthopaedic Surgical Patients: A Prospective Study. J Blood Disord Transfus 7: 339. doi: $10.4172 / 2155-9864.1000339$

Page 3 of 5

The clinical results are summarized in Table 2. In group A (40 patients) we performed the PABD'S program with the administration of ferrous bisglycinate chelate (one effervescent tablet/day=14 $\mathrm{mg} /$ day of elemental iron) for a period of 10 days before surgery procedure.

In group B (20 patients), all pts underwent the PABD'S program without Ferrous chelated bisglicinate therapy. For all pts were used for the same indications as the sampling procedure and autologous devices from the same collection.

All the patients carried out the study of the parameters established under basal conditions (immediately before PABD) and after ten days from PABD. The treatment with ferrous bisglycinate chelate started the same days of the PABD and lasted till 10 days after PABD.

All data were analyzed by a statistical evaluation (ANOVA procedure) for the two different groups of patients for every variable. We compared the difference in haemoglobin concentration $(\mathrm{Hb})$, percentage of reticulocytes (\% RET), serum ferritin (FER) and percentage of transferrin saturation (\%SAT) from the day of PABD to ten days after donation between the two groups.
Patient's results are summarized in Table 2. It was interesting to observe a statistical significance $(\mathrm{p}<0.0001)$ between groups for the clinical trial primary end-point $(\mathrm{Hb})$ and for one of the secondary endpoints evaluated, \%TSAT $(\mathrm{p}<0.0001)$.

For FER $(\mathrm{p}=0.155)$ and for \%RET $(\mathrm{p}=0.146)$ no statistical significance have been pointed out between the two groups

Also the increase in the proportion of circulating immature retycolocites (RETH) in comparison with mature component in the ferrous bysglicinate treated group suggests an increase of effective erythropoiesis by adding Ferrous Bysglicinate therapy to PABD.

Patients receiving oral iron therapy present a lesser iron depletion and an increased in erythropoiesis that limited $\mathrm{Hb}$ reduction due to PABD.

No side effects have been observed in the patients enrolled in the trial confirming that Ferrous bysglicinate chelate administered by oral route seems to possess a very interesting profile related to the absence of gastrointestinal adverse events.

\begin{tabular}{|l|l|l|}
\hline & Group A & Group B \\
\hline Number of patients & 40 & 20 \\
\hline Mean Age (years ) & 67.3 & 66,2 \\
\hline Male/Female $(n, \%)$ & $23 / 40$ & $12 / 20$ \\
\hline ASA physical classification & $2 / 3$ & $2 / 3$ \\
\hline THA $(n, \%)$ & $19(47 \%)$ & $10(50 \%)$ \\
\hline TKA $(n, \%)$ & $21(53 \%)$ & $10(50 \%)$ \\
\hline Mean Hb in CE (g/dL) & 12.3 & 12.7 \\
\hline ASA: American Society of Anesthesiologists; CE: Clinical Examination & & \\
\hline
\end{tabular}

Table 1: Patient demographics and surgical characteristics (San Camillo-Forlanini Hospital).

\begin{tabular}{|c|c|c|c|}
\hline \multicolumn{4}{|c|}{ Results } \\
\hline & $\begin{array}{l}\text { Group A } \\
\text { (Ferrous Bisglycinate Chelate plus PABD) }\end{array}$ & $\begin{array}{l}\text { Group B } \\
\text { (PABD) }\end{array}$ & $\begin{array}{l}\text { Statistical significance } \\
\text { (analysis of variance for repeated measures) }\end{array}$ \\
\hline Number of patients & 40 & 20 & \\
\hline$\Delta \mathrm{Hb}(\mathrm{g} / \mathrm{dL})$ & $-0.65 \pm 0.5$ & $-1.115 \pm 0.7$ & $p<0.0001$ \\
\hline$\Delta \operatorname{FER}(\mathrm{ng} / \mathrm{mL})$ & $-12.2 \pm 8$ & $-17.6 \pm 7$ & $p=0.155$ (n.s.) \\
\hline$\triangle \%$ TSAT & $-2.44 \% \pm 5.5$ & $-6.25 \% \pm 8.2$ & $p<0.0001$ \\
\hline$\Delta \% \mathrm{RET}$ & $-0.47 \pm 0.4$ & $-0.17 \pm 0.6$ & $p=0.166$ (n.s.) \\
\hline HRET & 1.18 & 4.73 & \\
\hline MRET & 8.28 & 11.1 & \\
\hline
\end{tabular}


Citation: Rondinelli MB, Inghilleri G, Pavesi M, Bartolomei AD, Pagnotta R, et al. (2016) Efficacy of Ferrous Bisglycinate Chelate for the Management of Preoperative Anaemia in Orthopaedic Surgical Patients: A Prospective Study. J Blood Disord Transfus 7: 339. doi: $10.4172 / 2155-9864.1000339$

Page 4 of 5

LRET

90.4

84.18

Table 2: Patient's results (San Camillo-Forlanini Hospital). $\Delta$ Hb: Difference between $\mathrm{Hb}$ at T0 (before PABD) and T1 (ten days later); $\Delta$ FER: Difference between FER at T0 (before PABD) and T1 (ten days later); $\Delta \%$ TSAT: Difference between $\%$ TSAT at T0 (before PABD) and T1 (ten days later); $\triangle \%$ RET: Difference between $\%$ RET at T0 (before PABD) and T1 (ten days later); HRET: Reticulocytes with High RNA counter; MRET: Reticulocytes with Medium RNA Counter; LRET: Reticulocytes with Low RNA Counter.

\section{Discussion}

Blood conservation is becoming a compelling and cost-effective measure for hospitals to improve their patient care. The scientific evidence has shown that red blood cell transfusions are associated with worse outcomes: subsequently, the patient blood management programs are being developed to reduce the use of allogeneic blood [19].

Reported adverse reactions to allogeneic blood, reduction of patients' survival and increase in infectious complications in the outcome of those patients receiving a larger number of allogeneic RBCc justify the hypothesis of a transfusion dose-related modulation of patients' defense with disruption of immune, biologic and metabolic equilibrium which is required for prompt recovery from major surgery and general narcosis [20]. A realistic and alternative approach to allogeneic blood transfusion is that of autologous blood collection preceded by correction of anemic conditions and, whenever possible, by expansion of $100 \%$ patient's circulating RBC volume. In our experience, the introduction of an integrated approach which includes $\mathrm{CE} / \mathrm{ST} / \mathrm{PABD} / \mathrm{PBC}$ produced an evident change in allogeneic $\mathrm{RBCC}$ usage in patients subjected to elective major surgery.

A key element during $\mathrm{CE}$ is the identification and diagnostic approach of preoperative anemia and its subsequent therapeutic treatment [21].

Preoperative anemia is common in patients undergoing orthopaedic and other major surgery. Anemia is associated with increased risks of post-operative mortality and morbidity, infectious complications, prolonged hospitalization and greater likelihood of allogeneic red blood cell transfusion [22].

Therefore it is mandatory to identify the etiology of anemia and begin a targeted therapy for its therapeutic resolution.

The critical issues reported by many authors using the PABD as a strategy for blood conservation is due to the frequent possibility of anemia of patients immediately before surgery [23].

The evaluation of the iron (martial) parameters and especially the availability of adequate therapy prevent the depletion of iron (martial) reserves, getting the golden standard of this multidisciplinary approach [24].

Our internal policy is to use the PABD in patients with high risk of bleeding and always in combination with a therapy that prevents a condition of anemia. This study reports our experience in an orthopedic surgery for 40 pts who have underwent a therapy with ferrous bisglycinate chelate, compared to 20 patients who performed the same surgery with the same integrated strategy and who have not received iron therapy.

The results shown that Pts receiving iron had a lesser extent of iron depletion and an increased erythropoiesis that limited $\mathrm{Hb}$ reduction due to predeposit. Surprising no side effects has been observed in pts receiving iron supplementation for 10 days and no one patient interrupted oral iron supplementation during home therapy: this "good compliance" to oral iron therapy could be useful in pre-surgical patient's management [25].

On the other side the difference on primary and secondary endpoints between groups related to the small amount of elemental iron containing in ferrous bysglicinate treated group $(14 \mathrm{mg} /$ day for only 10 days) seems to confirm the high oral bioavalability of this new and useful oral iron reparation.

Flow cytometry has also shown how Tecnofer therapy has been able to increase erythropoiesis through the increase of the share reticulocyte and erythrocyte differentiation.

We are still increasing the number of pre-surgical patients treated with ferrous bisglycinate chelate in order to consolidate these preliminary results.

This pilot clinical trial has a lot of methodological limitations due to the absence of a placebo-controlled group, the absence of the doubleblind design, the too short period of observation after PABD (only 10 days) and, obviously, the absence of the follow up of the intra and post surgical complications in the two different group of patients; nevertheless, the significant difference between groups in terms of $\mathrm{Hb}$ reduction and RET, TSAT and FER decrease due to Ferrous bysglicinate treatment, if confirmed in a placebo-controlled double blind clinical trial with adequate sample size of patients enrolled, could represent a very interesting new in patients pre-surgery management, allowing to ferrous bisglycinate chelate a specific role in this multidisciplinary approach.

\section{Acknowledgements}

The Authors thank to Anemo Association for scientific support.

\section{References}

1. Gombotz H (2011) Patient blood management is key before elective surgery. Lancet 378: 1362-1363.

2. Shander A, Van Aken H, Colomina MJ, Gombotz H, Hofmann A, et al. (2012) "Patient blood management in Europe". Br J Anaesth 109: 55-68.

3. Goodnough LT, Shander A (2013) Current status of pharmacologic therapies in patient blood management. Anesth Analg 116: 15-34.

4. Beattie WS, Karkouti K, Wijeysundera DN, Tait G (2009) Risk associated with preoperative anemia in noncardiac surgery: a single-center cohort study. Anesthesiology 110: 574-581.

5. Shander A, Knight K, Thurer R, Adamson J, Spence R (2004) Prevalence and outcomes of anemia in surgery: a systematic review of the literature. Am J Med 116 Suppl 7A: 58S-69S.

6. Musallam KM, Tamim HM, Richards T, Spahn DR, Rosendaal FR, et al. (2011) Preoperative anaemia and postoperative outcomes in non-cardiac surgery: a retrospective cohort study. Lancet 378: 1396-1407.

7. Bisbe E, Castillo J, Saez M, Santiveri X, Ruíz A, et al. (2008) Prevalence of preoperative anaemia and hematinic deficiencies in patients scheduled 
Citation: Rondinelli MB, Inghilleri G, Pavesi M, Bartolomei AD, Pagnotta R, et al. (2016) Efficacy of Ferrous Bisglycinate Chelate for the Management of Preoperative Anaemia in Orthopaedic Surgical Patients: A Prospective Study. J Blood Disord Transfus 7: 339. doi: $10.4172 / 2155-9864.1000339$

Page 5 of 5

for elective major joint orthopedic surgery. Transfus Alternat Transfu Med 10: 166-173.

8. Goodnough LT, Maniatis A, Earnshaw P, Benoni G, Beris P, et al. (2011) "Detection, evaluation and management of preoperative anaemia in the elective orthopaedic surgical patient: NATA guidelines". British Journal of Anaesthesia 106: 13-22.

9. Ashmead SD (2001) The chemistry of ferrous bis-glycinate chelate. Arch Latinoam Nutr 51: 7-12.

10. http://www.efsa.europa.eu/sites/default/files/scientific_output/files/ main_documents/299.pdf.

11. Mazza GA, Paolella G, Pedrelli L, Battaglia E, Giancotti L, et al. (2014) Oral iron absorption test in children with celiac disease and iron deficiency anemia: new insight for a forgotten test. Dig Liv Dis 46: e114.

12. Falco P (2013) Bisglycinated chelated iron in sideropenic anaemia treatment of celiac patients with refractoriness to the others iron therapies and improvement of laboratoristic haemoglobinic parameters. $44^{\circ}$ Congress of the Italian Society of Hematology. Verona.

13. Amè C, Campa E, Bertini M (2010) Trattamento dell'anemia sideropenica con ferro bisglicinato chelato (tecnofer) in pazienti con $\mathrm{m}$. celilaco non responders a terapia con Sali di ferro per os e/o ev. Abstract Book del XV Congresso Nazionale FADOI-Bologna 16-19 Maggio.

14. Amè C, Campa E, Bertini M (2010) Uso di ferro bisglicinato chelato (tecnofer) in pazienti con anemia sideropenica a diversa patogenesi non responders a terapia con Sali di ferro per os e/o ev. Abstract Book del XV Congresso Nazionale FADOI - Bologna 16-19 Maggio.

15. Iannello S, Spanti C, La Rosa R (2013) Efficacia e tollerabilità del ferro bisglicinato chelato (TECNOFER) nel trattamento dellanemia sideropenica lieve-moderata in pazienti donatori di sangue. J Health Sci 11:3-7.
16. Carson JL, Duff A, Poses RM, Berlin JA, Spence RK, et al. (1996) Effect of anaemia and cardiovascular disease on surgical mortality and morbidity. Lancet 348: 1055-1060.

17. Gruson KI, Aharonoff GB, Egol KA, Zuckerman JD, Koval KJ (2002) The relationship between admission hemoglobin level and outcome after hip fracture. J Orthop Trauma 16: 39-44.

18. Beattie WS, Karkouti K, Wijeysundera DN, Tait G (2009) Risk associated with preoperative anemia in noncardiac surgery: a single-center cohort study. Anesthesiology 110: 574-581.

19. Weiss G, Goodnough LT (2005) Anemia of chronic disease. N Engl J Med 352: 1011-1023.

20. Goodnough LT, Price TH, Rudnich S, Soegiarso RW (1992) "Preoperative red cell production in patients undergoing aggressive autologous blood phlebotomy with and without erythropoietin therapy. Transfusion 32 : $441-445$.

21. Goodnough LT, Brecher ME, Kanter MH, AuBuchon JP (1999) Transfusion medicine. Second of two parts--blood conservation. N Engl J Med 340: 525-533.

22. Pape A, Habler O (2007) Alternatives to allogeneic blood transfusions. Best Pract Res Clin Anaesthesiol 21: 221-239.

23. Stoneham M, Iqbal R (2007) Clinical strategies to avoid blood transfusion. Anaesthesia and Intensive Care Medicine 8: 52-55.

24. Auerbach M,Goodnough LT, Picard D, Maniatis A (2007) The role of intravenous iron in anemia management and transfusion avoidance. Transfusion 47: 1905-1918.

25. Pape A, Habler O (2007) Alternatives to allogeneic blood transfusions. Best Pract Res Clin Anaesthesiol 21: 221-239. 